\title{
THE IMPACT OF PERMEABILITY ENHANCERS ON ASSESSMENT FOR MONOLAYER OF COLON ADENOCARCINOMA CELL LINE (CACO-2) USED IN IN VITRO PERMEABILITY ASSAY
}

\author{
"Rastogi Himanshu ${ }^{1}$, Pinjari Jakir ${ }^{1}$, Honrao Pradnya ${ }^{1}$, Praband Suneel ${ }^{1}$, Somani Rahul ${ }^{2}$ \\ ${ }^{1}$ Drug Metabolism and Pharmacokinetics, Sai Life Sciences Ltd, Chrysalis Enclave, International Biotech Park, Phase II, Hinjewadi, \\ Pune 411057, INDIA \\ ${ }^{2}$ Sinhgad College of Pharmacy Vadgaon Budruk, Pune, 41105, INDIA \\ *Corresponding Author's E-mail: himanshurast@gmail.com, Tel: 91-20-66743600,Fax: 91-20-66743645, Mob: 91-9049822216
}

\begin{abstract}
The leading goal in new drug discovery is to have orally bioavailable drug. Poor permeability is one of the reasons for the poor bioavailability of several New Chemical Entities (NCEs). Permeability assessment using in vitro Caco-2 cell monolayer model is considered to be excellent model for screening of NCEs. Permeability enhancers can increase the permeability of compounds by paracellular or transcellular route. There are limitations to use the permeability enhancers due to concentration dependent toxic effect on cell monolayer, several times wrong interpretation can be made due to disrupted cell monolayer integrity. This study was performed on Caco-2 cell monolayer to identify optimal levels of commonly used permeability enhancers which does not cause any damage to the cell monolayer. The assessment involved pre and post TEER measurement and leak test using Lucifer yellow (LY) rejection assay. Total 16 permeability enhancers were tested and optimum levels were as per parenthesis: peanut oil (10\%), Cremphore EL, Miglyol 812, Oleic acid, Propylene glycol (1\%), Capmul MCM C8 EP, glycerol, Labrasol, MC8-2, PEG 400, Polysorbate 80, Sporiol TPGS, Transcutol (0.1\%), Capmul, Solutol (0.01\% ) and for PPS $(0.0001 \%)$. It was important to determine the optimal levels of each permeability enhancer to avoid any false positive results.

Keywords: Permeability enhancers, Caco-2 cell line, TEER, \% LY rejection, Tight Junctions
\end{abstract}

\section{INTRODUCTION}

Oral route is the most convenient route of drug administration. Several marketed drugs and New Chemical Entities (NCEs) are poorly soluble in aqueous media leading to problems in absorption from the gastrointestinal tract after oral administration. Penetration of these kinds of compounds via intestinal mucosa can be enhanced using absorption enhancers, which can increase the bioavailability and efficacy of a drug candidate [1].

There are several permeability enhancers which can help compounds to permeate through the intestinal barriers. These enhancers are surfactants, fatty acids, medium chain glycerides, steroidal detergents, acyl carnitine and alkanoylcholines, $\mathrm{N}$-acetylated $\alpha$-amino acids and $\mathrm{N}$ acetylated non- $\alpha$-amino acids, and chitosans and other mucoadhesive polyers [2]. Usage of permeability enhancers brings concerns of toxicity either in the GIT epithelium (in vivo) or disruption to the cell monolayer upon exposure (in vitro) [3]. This investigation aims to address and investigate the optimal levels of permeability enhancers which don't cause any damage to the cell monolayer [4].

To investigate the mechanisms involved in the bioavailability after oral administration Caco-2 monolayer model of epithelial cells have been widely used to study active and passive transport of drug molecules [5]. Caco-2 cell line is derived from a human colorectal carcinoma and these cells strongly express P-gp transporter [6]. Because of their tumorous nature this cell system is widely used in in vitro screening technologies to predict gastrointestinal absorption and possible Pgp transport of NCE's [7]. This model is also acceptable to FDA for in vitro evaluation of permeability for BCS Classification of drugs [8] and also for evaluating NCEs as a substrates and inhibitor of Pglycoprotein (P-gp, MDR1).

Caco- 2 cells when cultured on semi permeable membranes differentiate into a highly functionalized epithelial barrier and forms tight junctions with remarkable morphological and biochemical similarity to the small intestinal columnar epithelium [9]. The membrane transport properties of novel compounds can thereby be assessed using this differentiated cell monolayer. The apparent permeability coefficients (Papp) obtained from Caco-2 cell transport studies have been shown to correlate to human intestinal absorption.

This investigation will approach to summarize the optimal levels of absorption enhancer which do not cause any toxic effect on Caco-2 cell monolayer.

\section{MATERIALS AND METHODS}

\subsection{Chemicals and apparatus}

Dulbecco's Modified Eagles medium (DMEM) (Cat \# D5671), trypsin-EDTA solution (Cat \# T3924), Fetal Bovine Serum (FBS) (Cat \# 12003C), Hanks Balanced salt solution HBSS (Cat \# H6648), Lucifer yellow (L0529) and Loperamide (Cat \# L4762) were purchased from Sigma, Germany. 3-(N, N-Dimethylpalmitylammonio) propanesulfonate (PPS), Cremphore EL and Peanut oil were purchased from Sigma, USA. T-75 flasks and serological pipettes were purchased from Grenier-Bio-one, Germany. Mill cell -24 well PET membrane $1 \mu \mathrm{m}$ plates (Cat \# PSRP010 R5) were purchased from Millipore 
Corporation, Billerica MA. Labrasol and Transcutol were purchased from Gattefosse, Saint Priest cedex, France. Oleic aicid, Solutol HS 15 and PEG-400 were purchased from BASF, Germany. Glycerol and Propylene glycol were purchased from Merck, USA. Polysorbet 80 was purchased from Croda, Europe. Capmul, MC8-2 and Capmul MCM C8 EP were purchased from ABITEC, Jackson st. Janesvile. Sporiol TPGS was purchased from Cognis Pharma. Miglyol 812 was purchased from sasol, Germany

$\mathrm{CO}_{2}$ incubator (Thermo Scientific, 81 Wyman Street, Waltham, MA), Millicell ERS voltommeter (Millipore Corporation, Billerica MA), Centrifuge (Kubota, Tokyo, Japan), LC-MS/MS (Shimadzu Prominence LC-20AD, SIL-HTc, CTO-20AC, Japan; API-4000 MDS Sciex, Applied Biosystems, Canada), Micro plate Shaker (VWR) and Infinite F 200 PRO Multimode Reader (Tecan, Austria).

\subsection{Cell culture}

Caco-2 cells were procured from National Center for Cell Sciences (NCCS), Pune, India. The Caco-2 cells were cultured in DMEM supplemented with 10\% FBS and 2\% penicillin-streptomycin in a $37^{\circ} \mathrm{C}$ with $5 \% \mathrm{CO}_{2}$ humidified incubator. The cells were harvested at approximately 80 $90 \%$ confluency using $0.25 \%$ trypsin-EDTA (Ethylenediaminetetraacetic acid). The cells (passage number \# 36) were then seeded onto transwell inserts at a density of $0.8 \times 10^{5}$ cells $/ \mathrm{cm}^{2}$ and grown for 21 days. Medium was changed every alternative days and $100 \%$ confluent monolayer of cells on the inserts was used for transport assays. The formation of confluent monolayers and tight junctions was tested and confirmed by measuring transepithelial electrical resistance (TEER) across the cell monolayers from day 15 onwards.

\subsection{Dosing solutions preparations of permeability enhancer}

Different percentages of permeability enhancers are prepared as described below and shown in table 1.

- Capmul was weighed and liquefied at $45^{\circ} \mathrm{C}$ in water bath for 10 min to prepare $10 \%$ stock in HBSS (Hanks Balanced salt solution). These were further diluted to $1 \%, 0.1 \%$ and $0.01 \%$ using HBSS.

- Cremophore EL, glycerol, Labrasol, MC8-2, Miglyol 812, Oleic acid, Peanut oil, PEG 400, Polysorbet 80, Propylene glycol and transcutol was added to HBSS buffer to prepare $10 \%$ stock, which were further diluted to $1 \%$ and $0.1 \%$ using HBSS.

- PPS was weighed and stock of $1 \%$ is prepared in HBSS. These were further diluted to $0.01 \%, 0.001 \%$ and $0.0001 \%$ using HBSS.

- Spiriol TPGS, Solutol and Capmul MCM C8 was weighed and liquefied at $45^{\circ} \mathrm{C}$ in water bath for 10 min to prepare $10 \%$ stock in HBSS. These were further diluted to $1 \%$ and $0.1 \%$ using HBSS.

\subsection{Measurement of TEER}

The TEER test was performed using a Millicell ERS voltommeter, following equation was used to calculate the TEER values $\left(\Omega \mathrm{cm}^{2}\right)$ across the cell monolayers:

$$
\text { TEER }=\left(\mathrm{R}-\mathrm{R}_{\text {blank }}\right) \mathrm{A}
$$

Where, $\mathrm{R}$ is the measured resistance across a cell monolayer, $R_{\text {blank }}$ is the resistance of a blank well and $A$ is the surface area of the transwell filter $\left(0.7 \mathrm{~cm}^{2}\right)$. TEER values were measured and wells showing TEER values above $230 \Omega \mathrm{cm}^{2}$ were taken for experiments, indication of formation of a cell monolayer with tight junctions. TEER values were also measured at the end of assay (120 $\mathrm{min})$ to assess the toxic effects of permeability enhancers on the cell membrane's integrity.

Table 1: Summary table for different percentages of permeability enhancers used for assay

\begin{tabular}{|l|l|}
\hline Permeability enhancer & Percentage used for assay \\
\hline Capmul & $10,1,0.1$ and $0.01 \%$ \\
\hline Capmul MCM C8 EP & 10,1 and $0.1 \%$ \\
\hline CremphoreEL & 10,1 and $0.1 \%$ \\
\hline Glycerol & 10,1 and $0.1 \%$ \\
\hline Labrasol & 10,1 and $0.1 \%$ \\
\hline MC8-2 & 10,1 and $0.1 \%$ \\
\hline Miglyol 812 & 10,1 and $0.1 \%$ \\
\hline Oleic Acid & 10,1 and $0.1 \%$ \\
\hline PEG 400 & 10,1 and $0.1 \%$ \\
\hline Peanut Oil & 10,1 and $0.1 \%$ \\
\hline Polysorbate 80 & 10,1 and $0.1 \%$ \\
\hline PPS & $0.01,0.001$ and $0.0001 \%$ \\
\hline Propylene Glycol & 10,1 and $0.1 \%$ \\
\hline Solutol & $10,1,0.1$ and $0.01 \%$ \\
\hline Sporiol TPGS & 10,1 and $0.1 \%$ \\
\hline Transcutol & 10,1 and $0.1 \%$ \\
\hline
\end{tabular}

\subsection{Lucifer Yellow (LY) Rejection Assay}

Lucifer yellow travel across cell monolayer only through paracellular diffusion and has low permeability. As a result it's not possible to cross cell monolayer when tight junctions are well maintained. The integrity of the monolayer was measured by monitoring the lucifer yellow rejection, a paracellular marker across cell monolayer.

LY fluorescence (RFU) was measured at 485/535nm and the percent rejection of LY was calculated using formula:

$$
\% \text { LY Rejection = } 100\left[1-\mathrm{RFU}_{\text {basolateral }} / \mathrm{RFU}_{\text {apical }}\right]
$$

Where, RFU is relative fluorescence units. After the completion of last time point sampling (120 min), $100 \mu \mathrm{L}$ samples from apical and basal compartment was measured for lucifer yellow RFU. The \% LY rejection values > 99\% suggests the integrity of monolayer was maintained within duration of experiment.

\subsection{Transport studies}

Transport studies across the monolayer of Caco- 2 cells were performed by washing the cell monolayer twice with HBSS and incubated for $40 \mathrm{~min}$ in $\mathrm{CO}_{2}$ incubator. TEER values were measured and wells showing TEER values above $230 \Omega \mathrm{cm}^{2}$ were taken for experiments. 
Dosing solutions for different percentage of permeability enhancers prepared in HBSS were added on apical side of monolayer $(\mathrm{A} \rightarrow \mathrm{B}$ transport $)$ followed by adding $800 \mu \mathrm{L}$ of HBSS on basal side. After completion of experiment (120 min) samples were collected from apical and basal compartment for Lucifer Yellow Rejection followed by post experiment TEER values.

To assess the functionality of P-glycoprotein (P-gp) on Caco-2 cell monolayer loperamide was run as a positive control at $5 \mu \mathrm{M}$ concentration $(\mathrm{A} \rightarrow \mathrm{B} / \mathrm{B} \rightarrow \mathrm{A}$; $\mathrm{pH} 7.4$ / 7.4), study will be initiated by adding $400 \mu \mathrm{L}$ of loperamide prepared in HBSS in apical $(\mathrm{A} \rightarrow \mathrm{B}$ transport) followed by addition of $800 \mu \mathrm{L}$ of HBSS on basal side and for $\mathrm{B} \rightarrow \mathrm{A}$ transport $800 \mu \mathrm{L}$ of loperamide prepared in HBSS will be dosed in basal followed by addition of $400 \mu \mathrm{L}$ HBSS on apical side. At selected time points (0, 30, 60 and 120 minutes) an aliquot of $50 \mu \mathrm{L}$ will be collected from the receiver compartment for determination of test compound concentrations. The volume withdrawn will be replaced immediately with HBSS buffer. $50 \mu \mathrm{L}$ aliquot of test samples collected at respective time points were diluted with acetonitrile containing suitable internal standard were vortexed for 5 minutes and $100 \mu \mathrm{L}$ will be transferred to insert vials and analyzed using LC-MS/MS. Lucifer Yellow Rejection and TEER will be measured at the end to the experiment to confirm any damage of monolayer while performing experiment.

\subsection{Data Analysis}

The apparent permeability $\left(\mathrm{P}_{\text {app }}\right)(\mathrm{A} \rightarrow \mathrm{B}$ and $\mathrm{B} \rightarrow \mathrm{A})$ of test compounds and positive control will be calculated using the following formula:

$$
\mathrm{P}_{\mathrm{app}}=\mathrm{dQ} / \mathrm{dt} / \mathrm{A} \cdot \mathrm{C}_{\mathrm{o}}
$$

Where, dQ/dt - linear slope of test compound concentration in receptor chamber with time $(0,30,60$ and $120 \mathrm{~min}$ ) after correcting for dilution.

A - Area of the filter $\left(0.7 \mathrm{~cm}^{2}\right) ; \mathrm{C}_{\mathrm{o}}-$ Initial concentration of compound in the donor compartment.

Efflux ratio $\left(\mathrm{R}_{\mathrm{E}}\right)$ will be calculated using the following equation:

$$
\mathrm{R}_{\mathrm{E}}=\mathrm{P}_{\mathrm{B} / \mathrm{A}} / \mathrm{P}_{\mathrm{A} / \mathrm{B}}
$$

Where $\mathrm{P}_{\mathrm{B} / \mathrm{A}}$ and $\mathrm{P}_{\mathrm{A} / \mathrm{B}}$ represent the apparent permeability of test compound from the basal to apical and apical to basal side of cell monolayer. The compounds having efflux ratio of $>2$ is considered as having potential for P-gp substrate.

\section{RESULTS}

\subsection{Bi-directional transport of loperamide in Caco-2} cells

Bi-directional transport of loperamide was performed to assess the functionality of P-glycoprotein (P-gp) on Caco-2 cell monolayer. Apparent permeability coefficients (Papp) of Loperamide were calculated to assess the functionality of P-glycoprotein (P-gp) on Caco-2 cell monolayer is 5.04 $\mathrm{X} 10^{-6} \mathrm{~cm} / \mathrm{sec}$ for $\mathrm{A} \rightarrow \mathrm{B}$ transport and $16.6 \times 10^{-6} \mathrm{~cm} / \mathrm{sec}$ for $\mathrm{B} \rightarrow \mathrm{A}$ transport. Papp values for bi-directional transport of loperamide are shown in Table1. Loperamide showed an efflux ratio of 3.3 confirming that $\mathrm{P}$-gp is active in cell monolayer evident from Table 2 and Fig. 1 . The efflux ratio obtained with loperamide transport is within range as reported ${ }^{10}$.

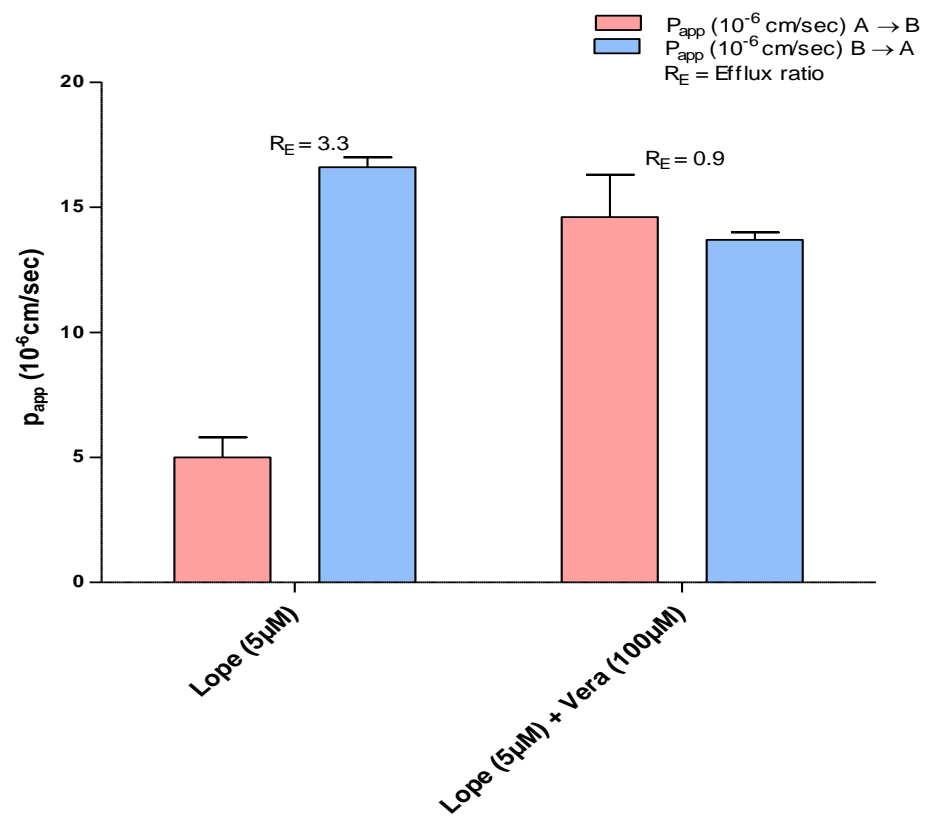

Figure 1: Bi-directional transport of loperamide across Caco-2 cells in absence and presence of P-gp inhibitor verapamil. The apparent $\mathrm{A} \rightarrow \mathrm{B}$ and $\mathrm{B} \rightarrow \mathrm{A}$ permeability (Papp; $10-6 \mathrm{~cm} / \mathrm{sec})$ of loperamide $(5 \mu \mathrm{M})$ showed an efflux ratio of 3.3 which dropped down to 0.9 in presence of P-gp inhibitor verapamil $(100 \mu \mathrm{M})$

\begin{tabular}{|c|c|c|c|c|}
\hline Compounds & No. of replicates & Concentration $(\mu \mathrm{M})$ & $\begin{array}{c}\text { Papp } \\
\left(10^{-6} \mathrm{~cm} / \mathrm{sec}\right)\end{array}$ & Efflux ratio $\left(R_{E}\right)$ \\
\hline Loperamide $(\mathrm{A} \rightarrow \mathrm{B})$ & 3 & \multirow{2}{*}{5} & $5.04 \pm 0.79$ & \multirow{2}{*}{3.3} \\
\hline Loperamide $(\mathrm{B} \rightarrow \mathrm{A})$ & 3 & & $16.6 \pm 0.4$ & \\
\hline Loperamide+ Verapamil $(\mathrm{A} \rightarrow \mathrm{B})$ & 3 & \multirow{2}{*}{5} & $14.6 \pm 1.7$ & \multirow{2}{*}{0.9} \\
\hline Loperamide+ Verapamil $(\mathrm{B} \rightarrow \mathrm{A})$ & 3 & & $13.7 \pm 0.3$ & \\
\hline
\end{tabular}

Table 2: Table representing Papp and efflux ratios of loperamide

3.2. Inhibition studies of loperamide with verapamil across Caco-2 cells
Addition of verapamil $(100 \mu \mathrm{M})$ to both compartments diminishes the P-gp mediated efflux. Inhibitory effect produced is observed through a decrease in loperamide 
Rastogi et al

Journal of Drug Delivery \& Therapeutics; 2013, 3(3), 20-29

$\mathrm{B} \rightarrow \mathrm{A}$ transport and an increase in $\mathrm{A} \rightarrow \mathrm{B}$ transport. Verapamil $(100 \mu \mathrm{M})$ significantly inhibited the loperamide $\mathrm{B} \rightarrow \mathrm{A}$ transport and improved $\mathrm{A} \rightarrow \mathrm{B}$ transport. The change in Papp values is depicted in Table 2 and Fig. $1 . A \rightarrow B$ and $\mathrm{B} \rightarrow \mathrm{A}$ Papp values for loperamide transport after addition of verapamil was found to be $14.6 \times 10^{-6} \mathrm{~cm} / \mathrm{sec}$ and $13.7 \mathrm{x}$ $10^{-6} \mathrm{~cm} / \mathrm{sec}$, respectively. After addition of P-gp inhibitor loperamide showed an efflux value of 0.9 confirming that $\mathrm{P}$-gp is active in cell monolayer.

\subsection{TEER measurements}

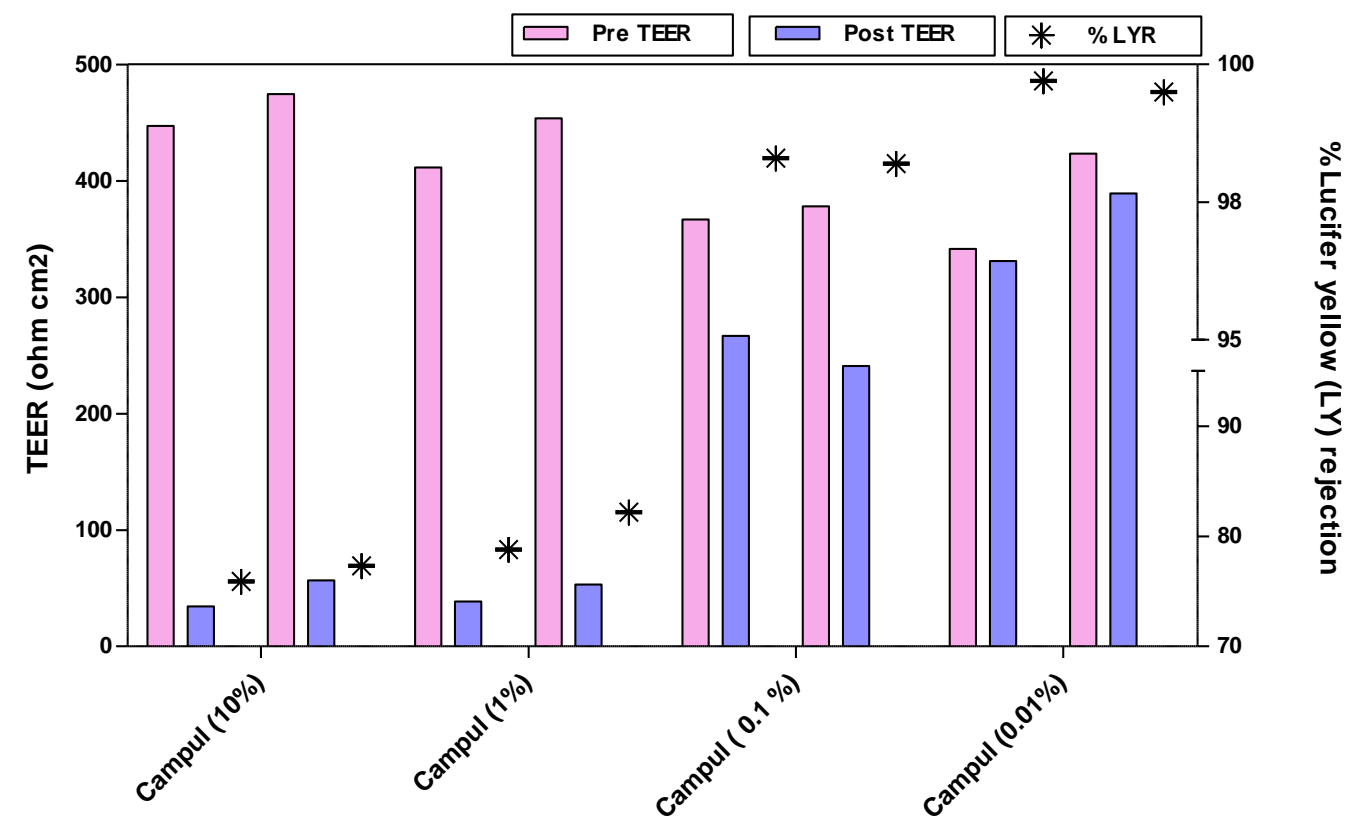

TEER measurements were made both prior to and at the end of experiment as drop in TEERs indicating the opening of tight junctions which might be due to toxicity caused by usage of various percentages of permeability enhancers, as evident in Fig. 2-17.

\section{4. \% LY rejection values}

Monolayer integrity was tested by Lucifer yellow (LY) rejection, percent rejection of $L Y$ was calculated and the various percentages of permeability enhancers showing values $<99 \%$ are considered to have toxic effect on Caco2 cell monolayer, as evident in Fig. 2-17.

Figure 2 - Pre and Post TEER along with \% Lucifer yellow (LY) rejection for Capmul. Four different percentages 10, 1, 0.1 and $0.01 \%$ of Capmul were used on Caco- 2 cell monolayer and no toxic effect was observed at $0.01 \%$

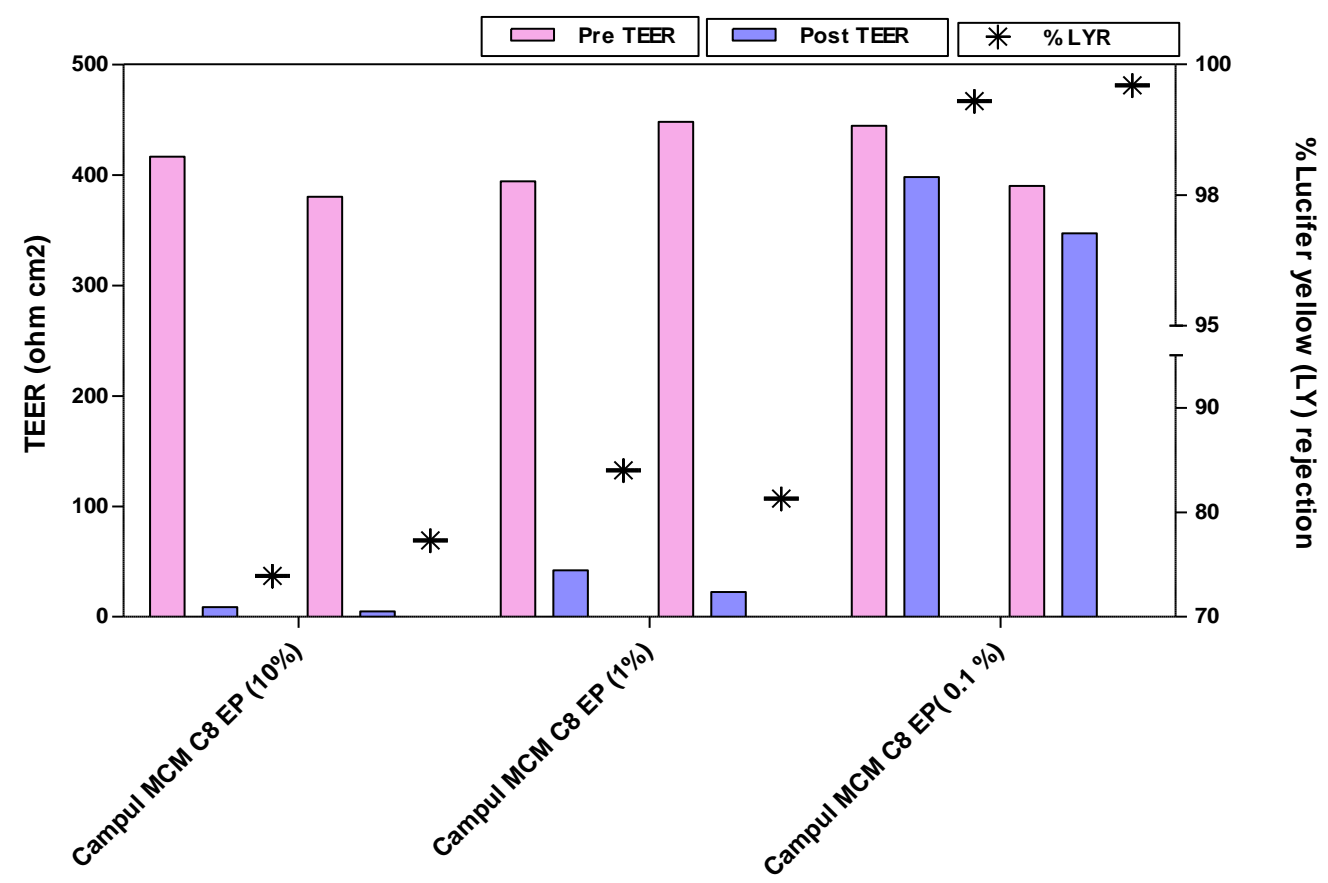

Figure 3 - Pre and Post TEER along with \% Lucifer yellow (LY) rejection for Capmul MCM E8. Three different percentages 10, 1 and $0.1 \%$ of Capmul MCM E8 were used on Caco-2 cell monolayer and no toxic effect was observed at 


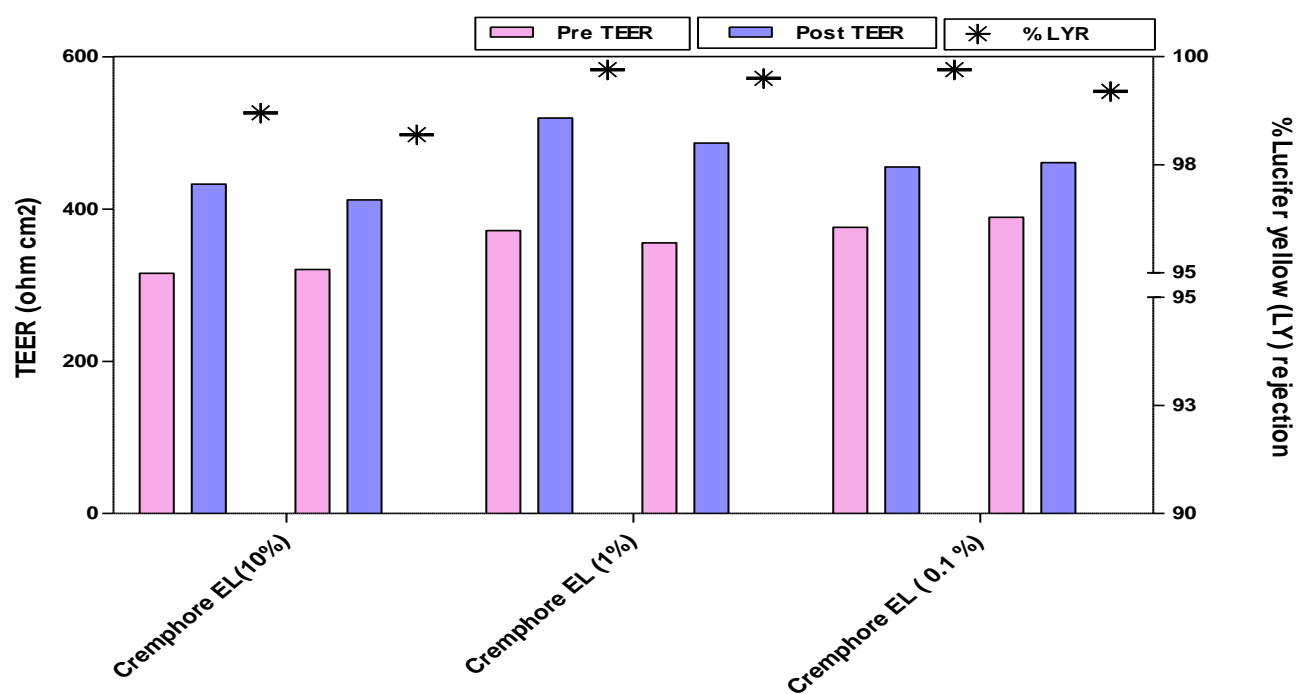

Figure 4: Pre and Post TEER along with \% Lucifer yellow (LY) rejection for Cremphore EL. Three different percentages 10,1 and $0.1 \%$ of Cremphore EL were used on Caco- 2 cell monolayer and no toxic effect was observed at $1 \%$

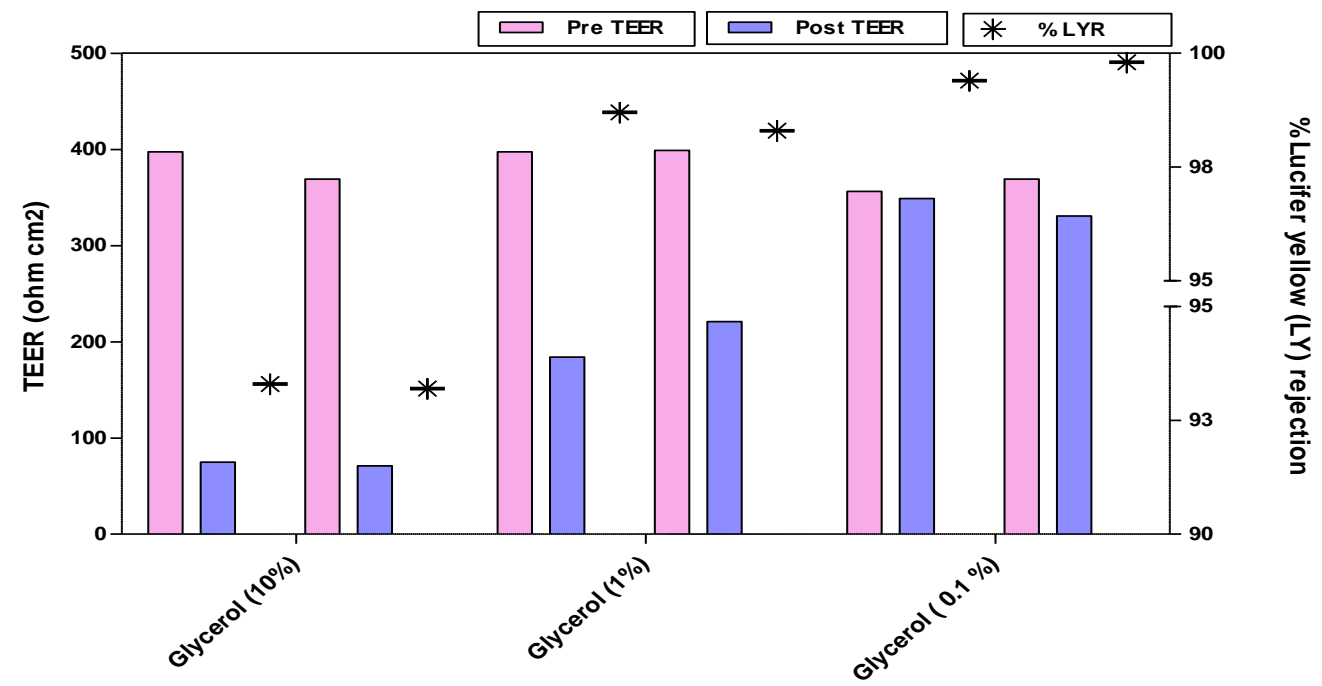

Figure 5 - Pre and Post TEER along with \% Lucifer yellow (LY) rejection for Glycerol. Three different percentages 10,1 and $0.1 \%$ of Glycerol were used on Caco- 2 cell monolayer and no toxic effect was observed at $0.1 \%$

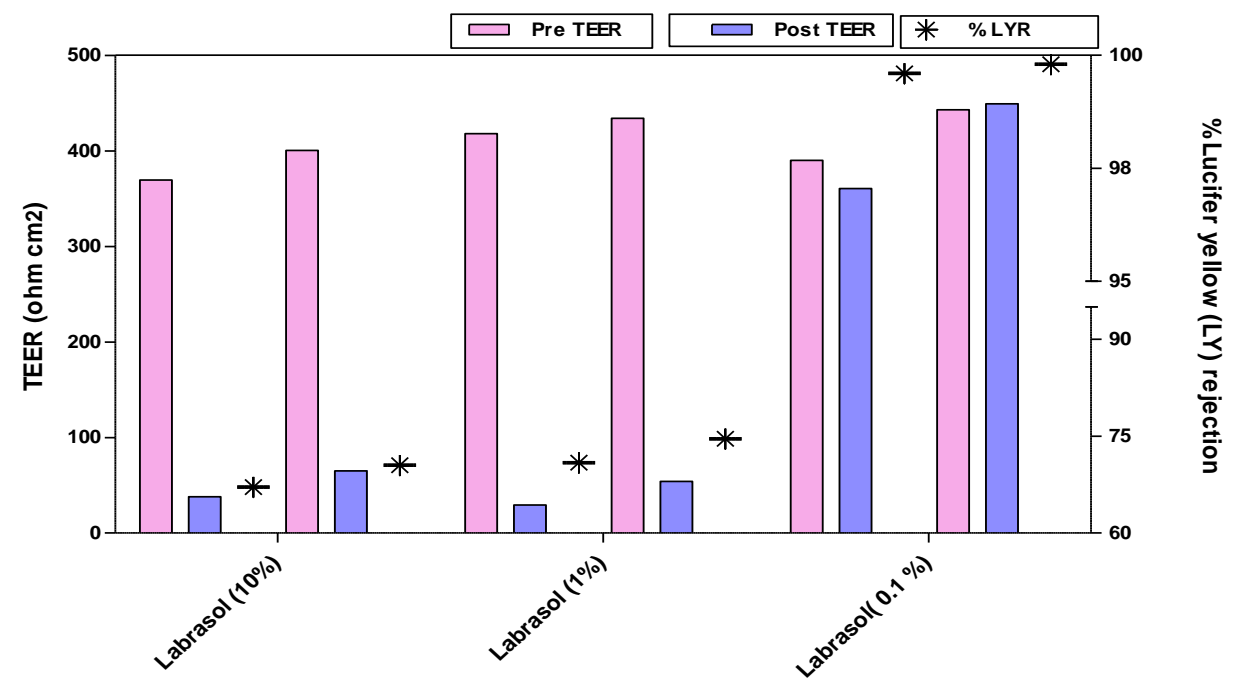

Figure 6 - Pre and Post TEER along with \% Lucifer yellow (LY) rejection for Labrasol. Three different percentages 10,1 and $0.1 \%$ of Labrasol were used on Caco- 2 cell monolayer and no toxic effect was observed at $0.1 \%$ 


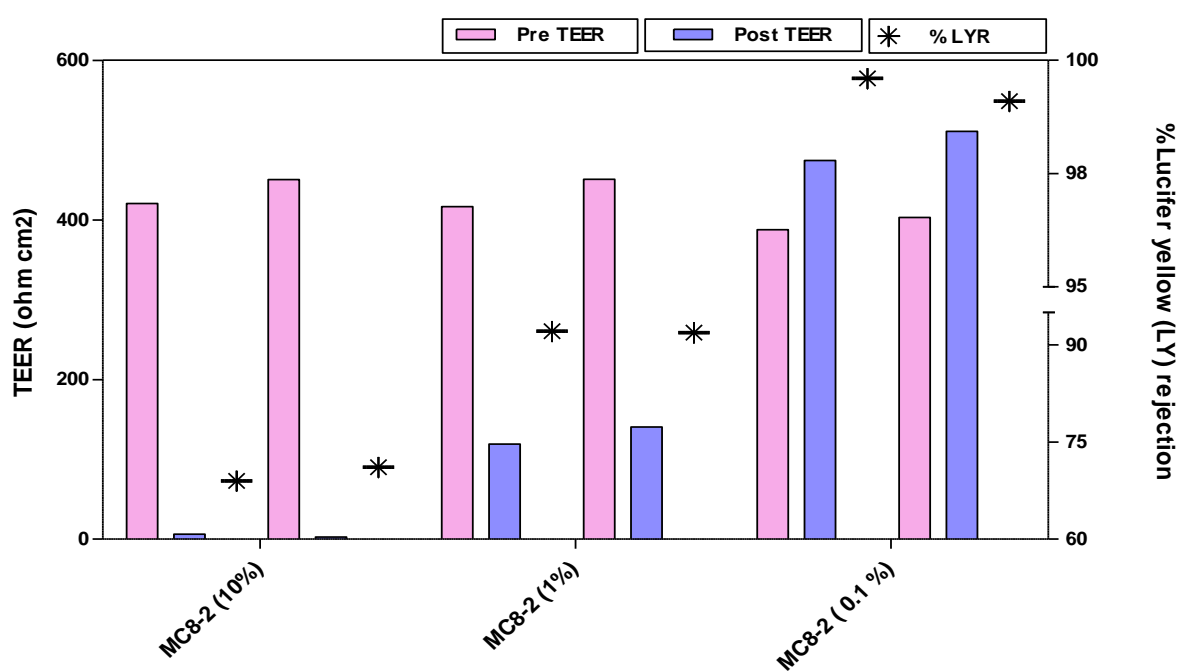

Figure 7 - Pre and Post TEER along with \% Lucifer yellow (LY) rejection for MC8-2. Three different percentages 10, 1 and $0.1 \%$ of MC8-2 were used on Caco- 2 cell monolayer and no toxic effect was observed at $0.1 \%$

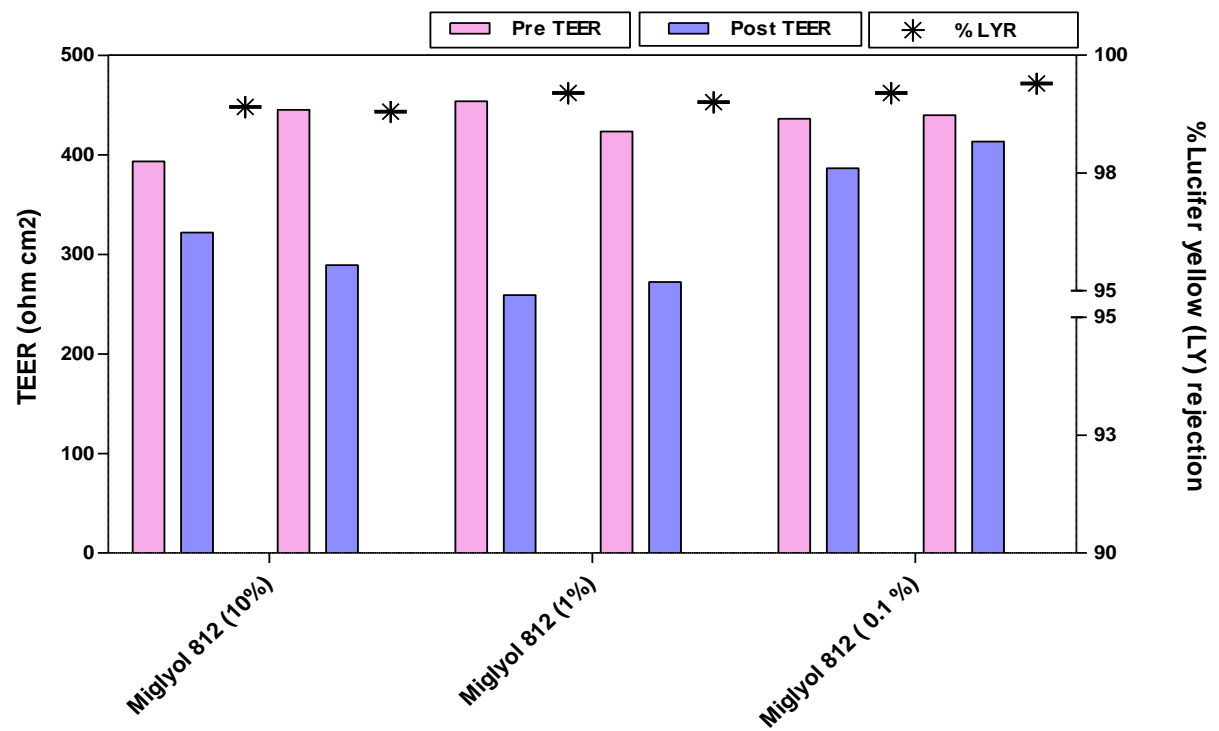

Figure 8 - Pre and Post TEER along with \% Lucifer yellow (LY) rejection for Miglyol 812. Three different percentages 10,1 and $0.1 \%$ of Miglyol 812 were used on Caco- 2 cell monolayer and no toxic effect was observed at $1 \%$

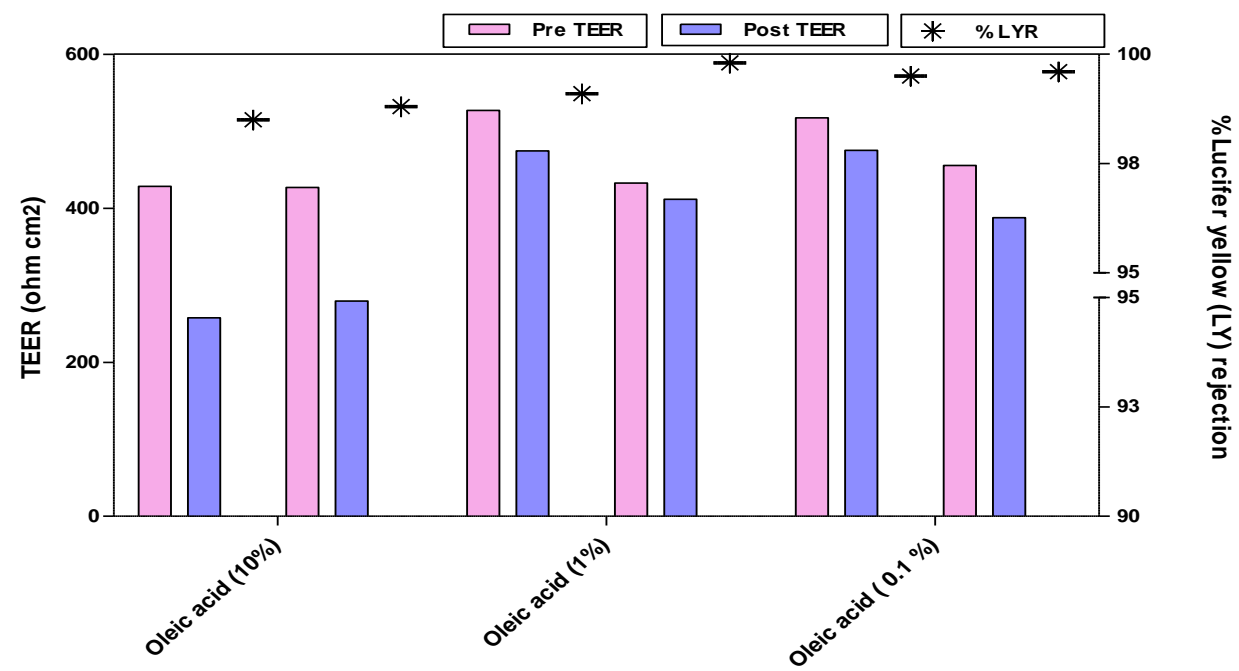

Figure 9: Pre and Post TEER along with \% Lucifer yellow (LY) rejection for Oleic acid. Three different percentages 10, 1 and $0.1 \%$ of Oleic acid were used on Caco- 2 cell monolayer and no toxic effect was observed at $1 \%$ 


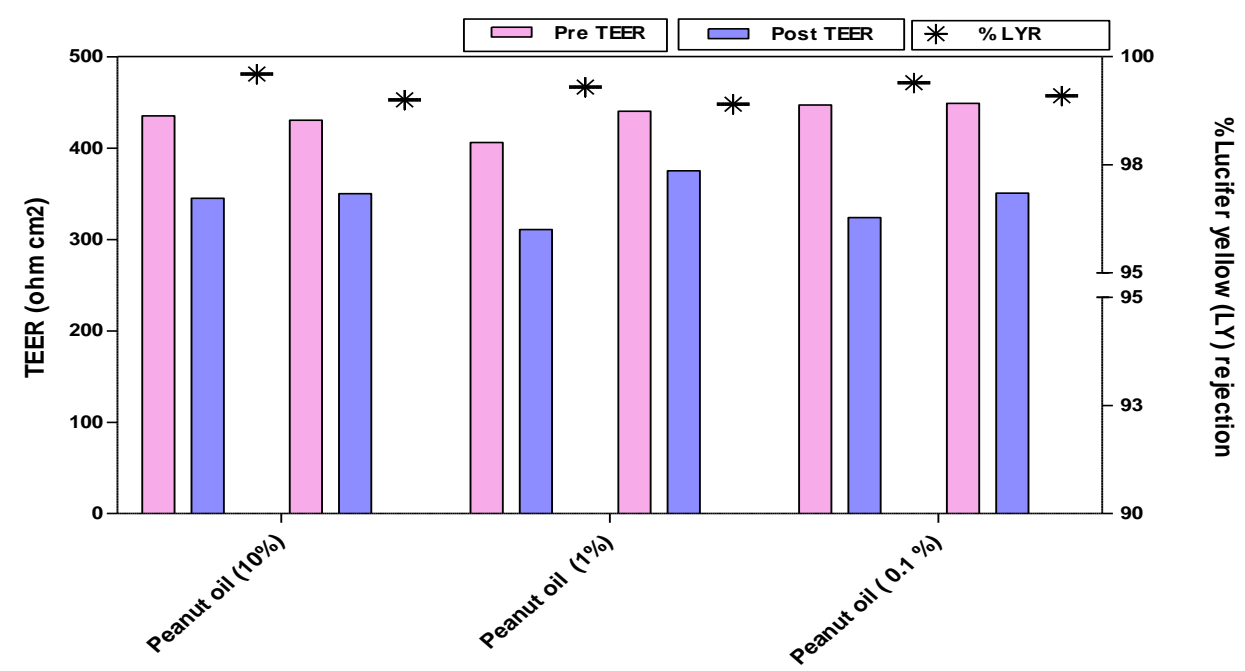

Figure 10: Pre and Post TEER along with \% Lucifer yellow (LY) rejection for Peanut oil. Three different percentages 10 , 1 and $0.1 \%$ of Peanut oil were used on Caco- 2 cell monolayer and no toxic effect was observed at $10 \%$

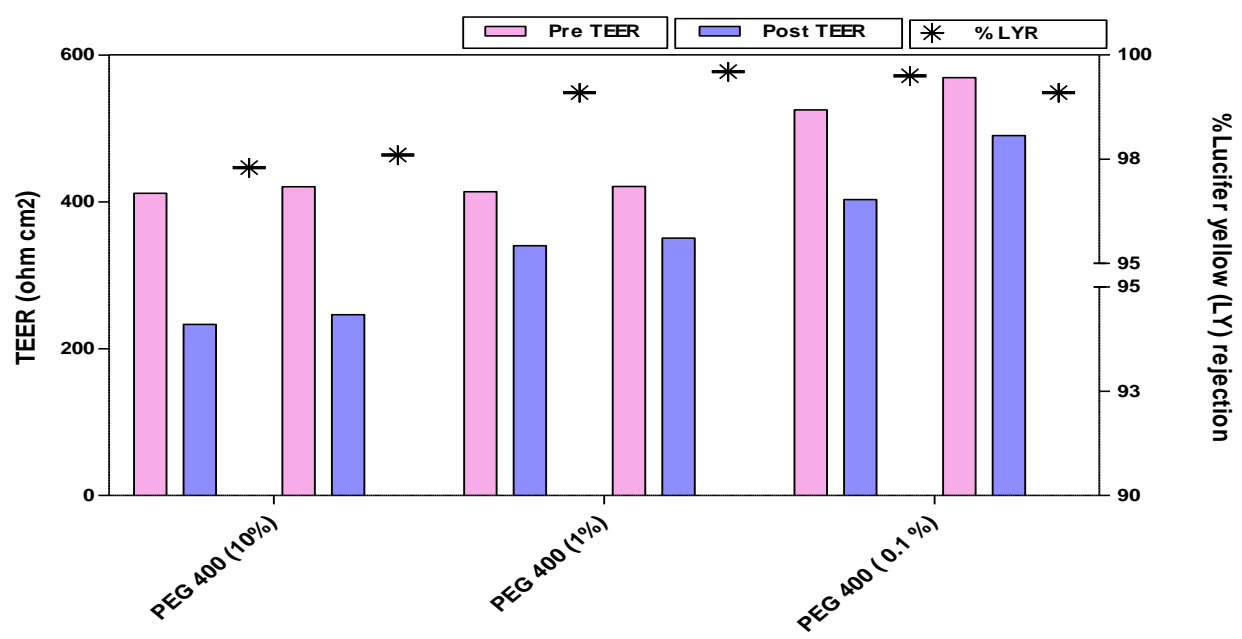

Figure 11: Pre and Post TEER along with \% Lucifer yellow (LY) rejection for PEG 400. Three different percentages 10,1 and $0.1 \%$ of PEG 400 were used on Caco- 2 cell monolayer and no toxic effect was observed at $0.1 \%$

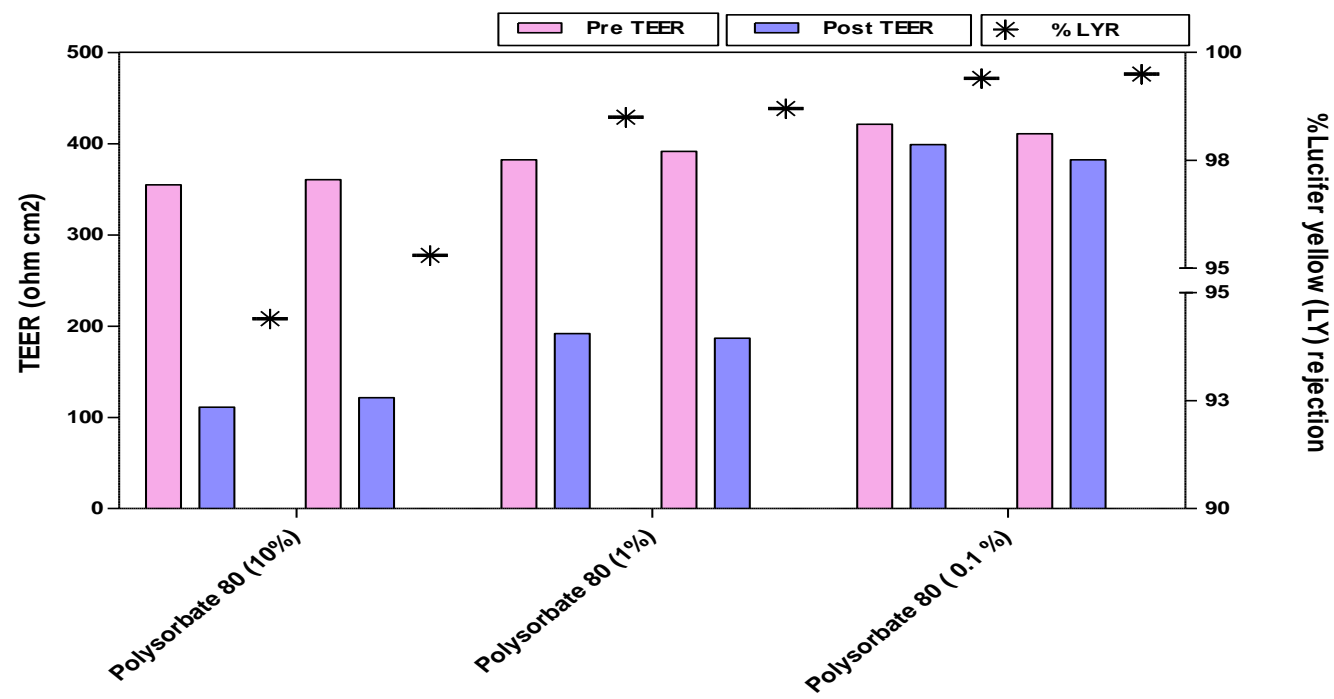

Figure 12: Pre and Post TEER along with \% Lucifer yellow (LY) rejection for Polysorbate 80. Three different percentages 10,1 and $0.1 \%$ of Polysorbate 80 were used on Caco-2 cell monolayer and no toxic effect was observed at $0.1 \%$ 


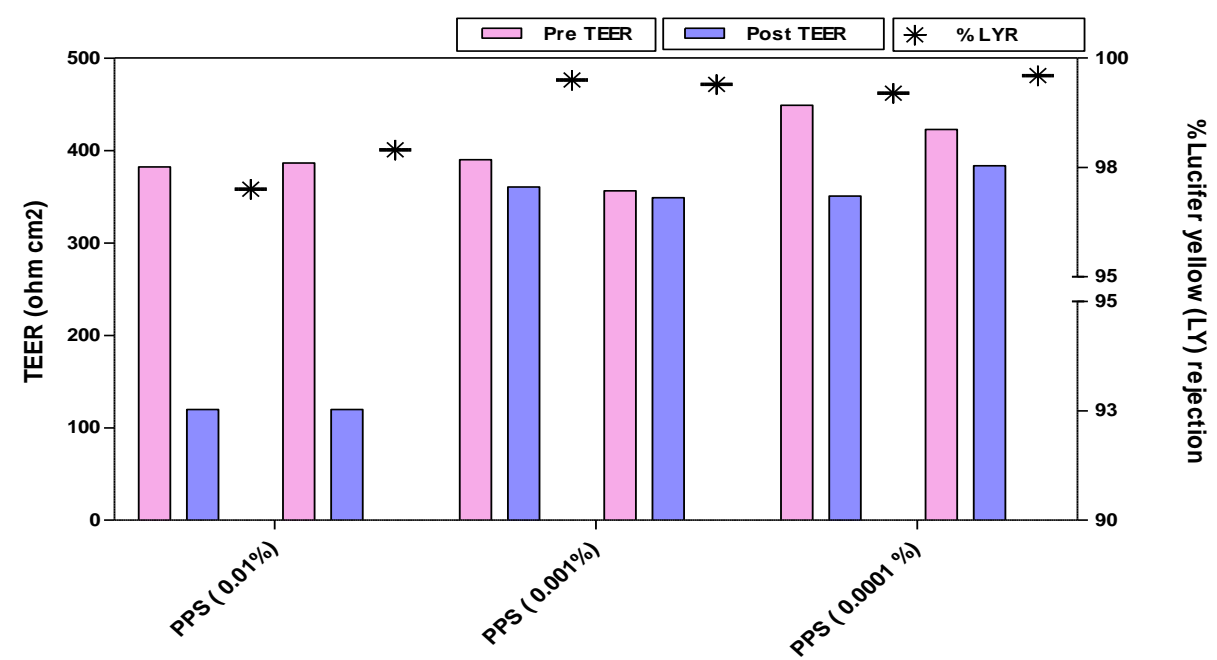

Figure 13: Pre and Post TEER along with \% Lucifer yellow (LY) rejection for PPS. Three different percentages 0.01 , 0.001 and $0.0001 \%$ of PPS were used on Caco- 2 cell monolayer and no toxic effect was observed at $0.0001 \%$

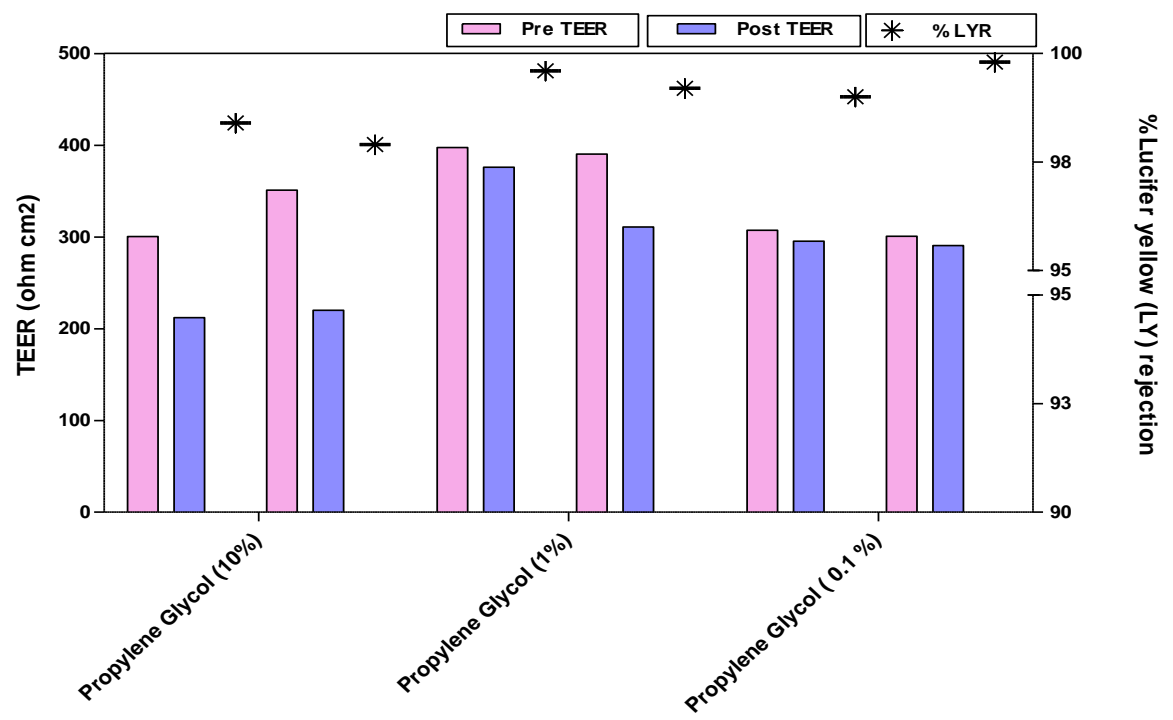

Figure 14: Pre and Post TEER along with \% Lucifer yellow (LY) rejection for Propylene Glycol. Three different percentages 10, 1 and $0.1 \%$ of Propylene Glycol were used on Caco-2 cell monolayer and no toxic effect was observed at $1 \%$

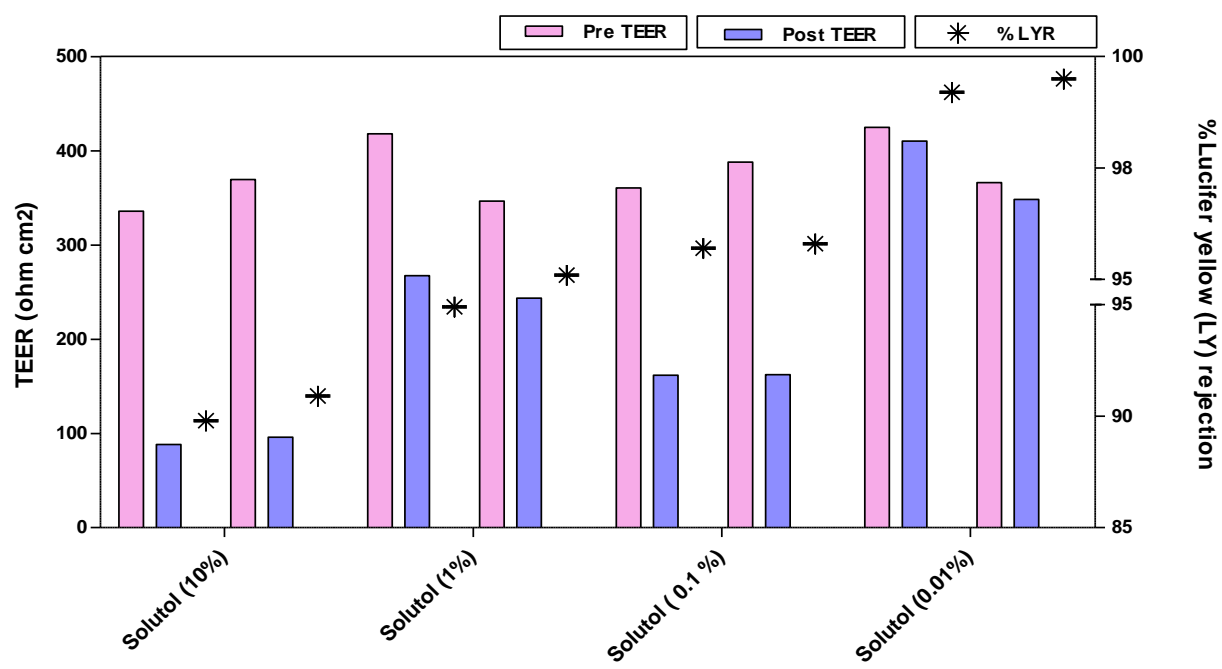

Figure 15: Pre and Post TEER along with \% Lucifer yellow (LY) rejection for Solutol. Four different percentages 10, 1 , 0.1 and $0.01 \%$ of Solutol were used on Caco-2 cell monolayer and no toxic effect was observed at $0.01 \%$ 


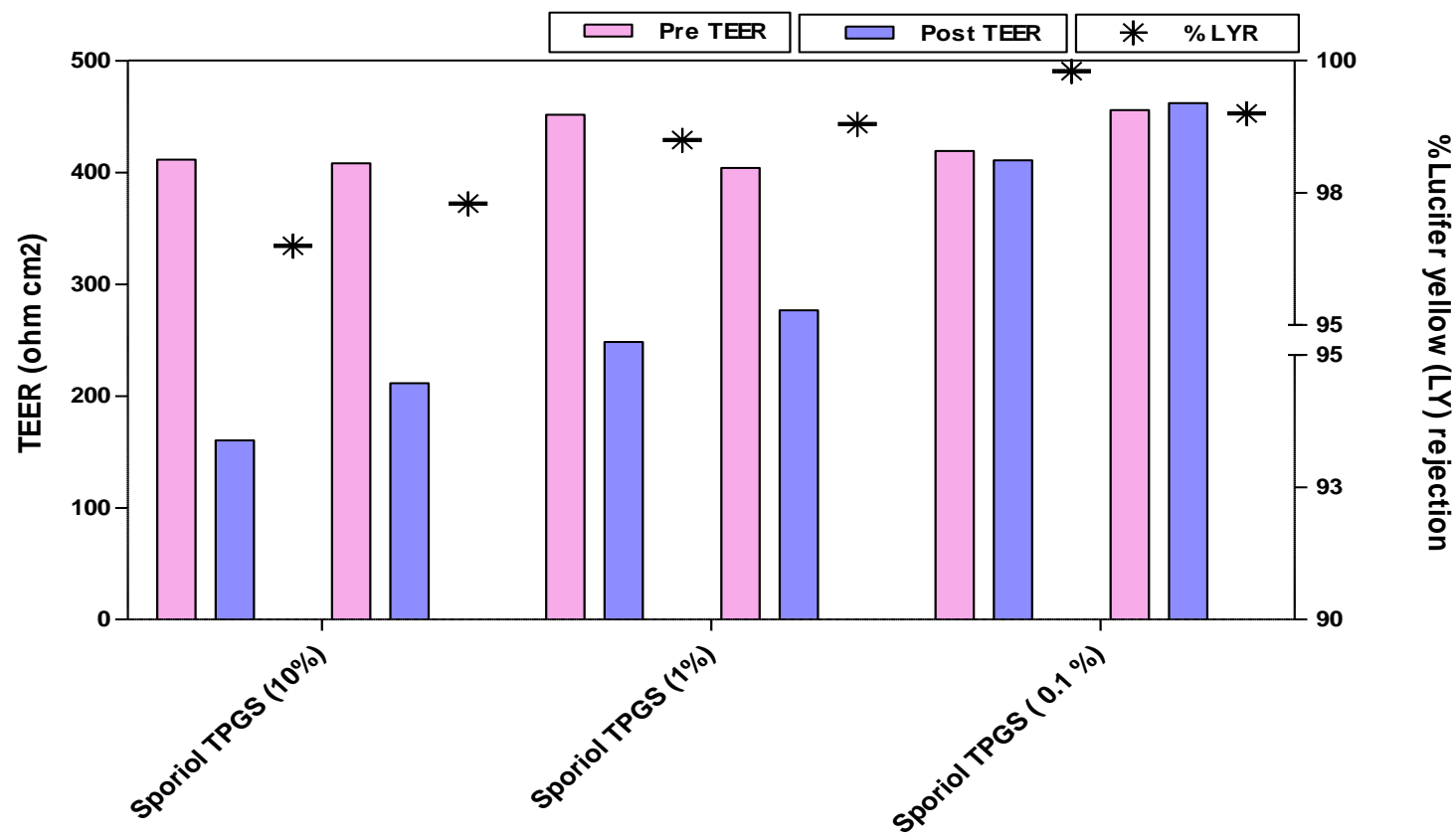

Figure 16 - Pre and Post TEER along with \% Lucifer yellow (LY) rejection for Sporiol TPGS. Three different percentages 10,1 and $0.1 \%$ of Sporiol TPGS were used on Caco-2 cell monolayer and no toxic effect was observed at $0.1 \%$

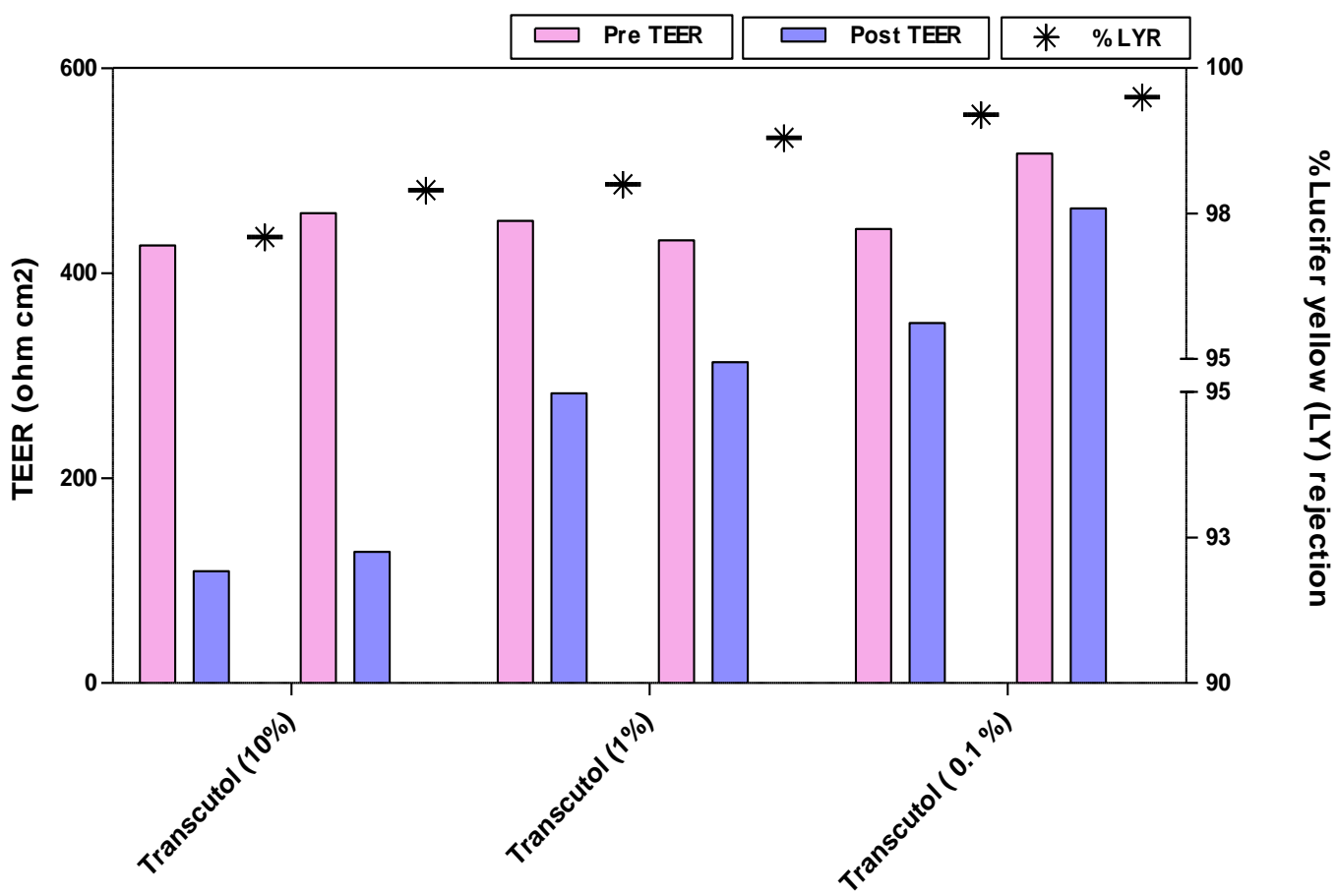

Figure 17 - Pre and Post TEER along with \% Lucifer yellow (LY) rejection for Transcutol. Three different percentages 10 , 1 and $0.1 \%$ of Transcutol were used on Caco- 2 cell monolayer and no toxic effect was observed at $0.1 \%$

\section{DISCUSSION}

Compiling the data generated by pre and post TEER measurement and leak test using Lucifer yellow (LY) rejection assay as evident in Fig. 18, the ideal levels of permeability enhancer which is not toxic to cell monolayer are as per parenthesis: peanut oil (10\%), Cremphore EL,
Miglyol 812, Oleic acid, Propylene glycol (1\%), Capmul MCM C8 EP, glycerol, Labrasol, MC8-2, PEG 400, Polysorbate 80, Sporiol TPGS, Transcutol $(0.1 \%)$, Capmul , Solutol (0.01\%) and for PPS (0 .0001\%). 


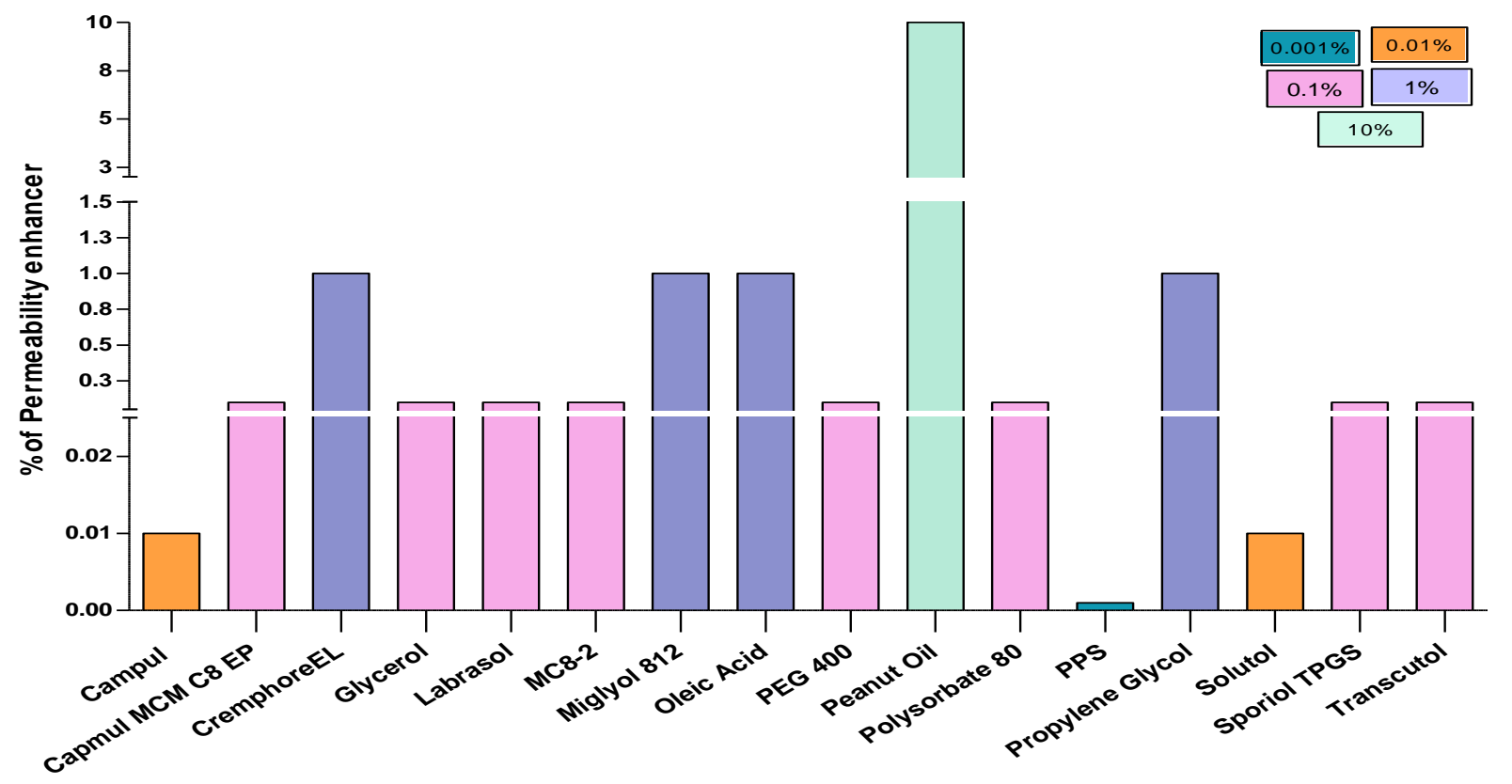

Figure 18 - Ideal percentage of permeability enhancers on Caco-2 monolayer

\section{CONCLUSION}

This article addresses the optimum levels of commonly used permeability enhancers in Caco- 2 cell lines to predict the oral bioavailability These enhancers generally increases the intestinal membrane permeability which is similar to Caco- 2 cell monolayer permeability. The critical issue considered in evaluating this approach is the toxic effect and damage of cell monolayer by the usage of permeability enhancers. The categories of permeation enhancers discussed are surfactants, fatty acids, medium chain glycerides, steroidal detergents, acyl carnitine and alkanoylcholines, $N$-acetylated $\alpha$-amino acids and $N$ acetylated non- $\alpha$-amino acids, and chitosans and other mucoadhesive polyers. This can be a potential approach in selecting appropriate enhancer to improve oral bioavailability of poorly absorbed compounds. This will reduce the attrition during in vivo assessment of oral bioavailability improvement.

\section{ACKNOWLEDGEMENTS}

Authors are thankful to Sai Life Sciences Ltd for providing all the necessary facility support to carry out the work successfully and the members of the Sai Life Sciences Ltd who have helped directly and indirectly to the work discussed in this manuscript.

\section{Conflict of Interest Statement}

The authors confirm that there are no conflicts of interest.

\section{REFERENCES}

1. Aungst BJ, Intestinal permeation enhancers. J Pharm Sci. 2000, 89, 429-42.

2. Calcagno AM, Ludwig JA, Fostel JM, Gottesman MM, and Ambudkar SV, Comparison of drug transporter levels in normal colon, colon cancer, and Caco-2 cells: impact on drug disposition and discovery, Mol Pharm 2006, 3,87-93.

3. http://www.fda.gov/cder/drug/drugInteractions/default.htm

Guidance for Industry: Drug Interaction Studies — Study Design, Data Analysis and implications for Dosing and Labeling. FDA September 2006 Clinical Pharmacology.

4. http://www.fda.gov/cder/guidance/index.htm Guidance for Industry: Waiver of In Vivo Bioavailability and Bioequivalence Studies for Immediate-Release Solid Oral Dosage Forms Based on a Biopharmaceutics Classification System. FDA August 2000 BP.

5. Hidalgo IJ, Raub TJ, and Borchardt RT, Characterization of the human colon carcinoma cell line (Caco-2) as a model system for intestinal epithelial permeability, Gastroenterology 1989, 96, 736749.

6. Michael H., Eric H., Sang P. and Peng A., Effect of permeability enhancers for polar drug transport across Caco-2 cell monolayers. AAPS annual meeting 2008; Atlanta, GA.

7. Remington: The Science and Practice of Pharmacy, ExtendedRelease and targeted drug delivery system. Xuan Ding, Adam WG Alani, Joseph R Robinson. Lippincott Williams \& Wilkins, USA; 2006. P. 939-964.

8. Romsicki, Y., Sharom, F.J., The membrane lipid environment modulates drug interactions with the P-glylcoprotein multidrug transporter. Biochemistry 1999, 38, 6887-6896.

9. Smart JD, The basics and underlying mechanisms of mucoadhesion. Adv. Drug Del. Rev. 57 2005, 1556-1568.

10. Stoner, C.L., Whittico, M.T., Fountain, S.T., Buchholz, L.M., Surendran, N., Chan, O.H., Stewart, B.H., Oh, D.M., High throughput P-glycoprotein interaction screening in Caco-2 cells for drug discovery compounds. AAPS Annual conference 2000; Indianapolis. 